\title{
The influencing on the segmentation of consumers to use of the theory planned behavior (TPB) based on the lifestyle in Tehran City
}

\author{
Abdollah Naamei ${ }^{1}$, Fataneh Alizadeh Meshkani ${ }^{2}$, Mitra Tavassoli ${ }^{3}$ \\ ${ }^{1}$ Assistant Professor Department of industry Management, Faculty of Management \& Accounting, Tehran \\ south Branch Islamic Azad University, Iran \\ ${ }^{2}$ Assistant Professor Department of industry Management, Faculty of Management \& Accounting, Tehran \\ south Branch Islamic Azad University, Iran \\ ${ }^{3}$ Student Master of Business Administration Marketing, Tehran south Branch Islamic Azad University, Iran
}

\begin{abstract}
The purpose of this paper is to identify of factors of segmentation of markets and consumers based on lifestyle, household appliances exhibition for visitors from various aspects to be studied not only the segmentation of market formation to affect people's lifestyle, but also the behavior and perceptions of consumers affected based on attitude, behavior, put the appliance on consumers to visit the exhibition a considerable effect on market size and segmentation of the consumer lifestyle. This research is descriptive survey can be applied for aims. To the hypothesis of structural equation modeling with partial least squares approach is used. In this study we have used the software's is like SPSS and Smart pls. The study population four regions of Tehran residents, based on the theory of planned behavior Ajzen, to investigate the behavioral attitude, subjective norms and perceived visitors to the exhibition appliance based on Lifestyle. For this purpose, after determining the validity and reliability of the questionnaire, using random sampling, the number of 392 questionnaires were distributed and path analysis were used to analyze the data. Path analysis showed that attitude toward the behavior, subjective norms, and perceived behavioral control directly on home appliances exhibition visitors will have a significant effect on the model of behavior between the two groups have not difference between the lifestyle .
\end{abstract}

Keywords: visitors, the theory of planned behavior, lifestyle, theory of logical operations, household appliances exhibition

\section{Introduction}

Today, there are competitive highly in global economic environment and the business centers are therefore acknowledge. In such a business environment and maintain the position of market segmentation and target markets have prompted large corporations today appliance from its power to create comfort for the buyers of life, and the special services step-by-new see fresh toys attracting the attention of buyers and visitors to the market every day. But the main importance of this approach to exhibitions has been little development of household appliances in recent years.

Exhibition can be a strong motivation for sales people and to the growth of household appliances exhibitions that are based on market segmentation to increase their effectiveness.( Bessiere,2010).

For market segmentation was important shopping experiences, therefore the product selection were tools for planning to purchase home appliances is an important part in trade fairs (Ignatov \& Smith ,2006)

Given the importance of exhibitions and experiences, shopping, household appliances exhibition has become an important element for visitors is considered (Smith \& Xiao 2008). However exhibitions household appliances were creativity and new ideas to bring products to visitors and this can help marketing strategy and maximize limited resources. (Teo \& Chang.2012) Identify theory of planned behavior for visitors were used to the exhibition household appliances that can be apply to the development and production of advanced technology and attract Technology competitive products to everyone that we can compete for exhibitions of household appliances on the market and which had outlined consumers different life styles .

On the other hand, the behaviors of individuals were as household appliances exhibition visitors, influence attitudes, motivation, attitudes, norms and so on. A wide variety of these factors had formation on the behavior of visitors in line with market segmentation and life style.

\section{The theory of reasoned action or argument}

\section{Literature review}

Theory of Reasoned Action created in 1967, represents the logical models to predict action plan Specific behavior, as well as decisions about surgery or not the desired behavior. 
The theory can be used in a variety of populations and behavior. This theory have accurately predict power about important aspects of consumer behavior and decision-making in customers' decisions and consumer behavior

The theory advanced to explain any behavior that a person can control and to use them. This model assumes that determines the behavior directly, the others factors that have influence on the behavior of intent should be indirect. Any case of measures of aim were in the framework of the action, aim, position and time two factors:

To be treated correctly predicted. The power of intention to perform a certain behavior is the result of

\section{Attitude to behavior}

\section{The influence of social environment or general subjective norms in behavior}

Attitudes and subjective norms were each two elements as like attitude to behavior have by faith of individuals. The results of Evaluation behavior is known person. In using this model in consumer behavior includes issues such as market segmentation based on customers based on lifestyle.

Therefore, subjective norm based on normative beliefs that other people have thinks based on the motivations of person in compliance that should be determined them.

\section{Theory of Planned Behavior}

One of the best theories about predictors of behavior was theory of planned behavior. This theory of attitudes, subjective norms, and perceived behavioral control, intention and is intention and behavior. According to this theory intention of individual to perform the behavior driven by three factors:

1. Belief of individual will result follow and they have evaluate by individual (behavioral beliefs)

2. Opinion about the normative expectations of others and motivated person to fit these expectations (normative beliefs)

3. Belief about the presence of facilitators or barriers perceived power of each of these factors (beliefs control). Behavioral beliefs had to be attitudes toward behavior for desirable or undesirable. Normative beliefs result in perceived social pressure or subjective norms and perceived behavioral control are creating beliefs controls. Attitude toward the behavior was including as subjective norms, and perceived behavioral control for formation of intention of behavior.

As a basic rule, an attitude of desired toward behavior and suitable subjective norms and perceived control was as behavior that individual should be very intention doing behavior. Finally to identify a sufficient degree of real control over the behavior of people expected if the opportunity is available, people have operate intention of their behavior. So, we assume that the intention predictor is immediate behavior.

However, because of some behavior may to problems executive for control. (Lazer. 2010)

In addition, the control of behavior was very useful for intention. Whatever the perceived behavioral control was real, which can be used as a proxy for the actual control and can also help in predicting the behavior. (Godin J., 2009)

\section{Theory and Hypothesis}

\section{4-1. Attitude toward behavior}

The first factor have influence to the intention of people to behavior or lack of behavior, an attitude and trend were as factors personal an aim of attitude had evaluated negative or positive a personal for doing or the absence of behavior is characterized. But attitude of personal was negative to behavior .According to these theory is attitude of personal for doing positive a behavior. According to this theory the person's attitudes was about an object for performance and evaluate the result of individual beliefs in connection with these ideas. The opinions are as the basis object for the formation of an attitude toward an object. Attitudes are usually determined by assessing a person's opinion. Always, attitudes are determined by assessing a person's opinion. It is obvious that in order to determine the cause of formation were considered to change of attitude and intention of people.

In general, beliefs was refers to the possibility of subjective judgment of one's views in relation to many aspects of distinct world around one. They are associated with one's appreciation of their environment.(Ajzen,1978)

\section{4-2.Subjective Norms}

The second factor is that have influence to intention of people behavior or lack of behavior. Subjective norms that is relevant to social factors. Subjective norms of social pressures were associated with the person of understanding, which enters on the personal to do something or not to do Social norms are applicable regulatory standards for which can accept or reject them. For example, it must be said that many people in Iran at the beginning of market segmentation clear attitude in relation to there aren't the lifestyle for people. 
The influencing on the segmentation of consumers to use of the theory planned behavior (TPB) ..

\section{4-3 Perceived Behavior Control}

The third factor to carry out the intent of behavior or lack of behavior influences the behavior is perceived. The theory of planned behavior is definition perceived behavioral control as difficult or easy for an individual assessment of behavior Perceived behavioral control, when determining behavior that is concerned reflects real control on the behavior of individuals. There are a number of environmental and organizational factors that can perform a certain behavior easier or more difficult to make.

It is assumed that perceived behavioral control reflects the individual's previous experience barriers was predicted a behavior.

\section{4-4 Behavioral Intention}

A major factor in the theory of planned behavior, intention to perform the behavior is specified. It is assumed that the intention of the motivational factors that affect the behavior of controls .intention of behavior refers to a person's behavior is to perform a specific behavior. Being strong is shown an intention by a person's subjective probability that a person will do the desired behavior. In the Theory of Planned Behavior and Theory of Reasoned Action, this predictor of behavioral intentions is more important. It is assumed to that the desirable attitude about some of the causes that he wants to do positive behavior and less negative behavior intended to take the matter to do. Behavioral intentions were combination of programs of action and motivation of individuals to engage in a certain behavior is summarized. Thus people who are motivated to do a behavior are more likely to do it successfully.TPB is the origin of the idea of doing any behavior by both intention and perceived behavioral control can be specified.

\section{4-5-Life Style}

Lifestyle that is how lives a person with others. Family and lifestyle is a lifestyle influenced by the style of family life and vice versa is also true.

Subculture of people who belong to the same social class and even jobs are the same, may have different life style. The lifestyle of a living person in the activities, interests and personal thoughts are expressed. Lifestyle is something more than personality or social class person. Perfect pattern of action and reaction lifestyle including one in the world.

As a result of a combination of lifestyle factors such as culture, values, resources, and law, and is reflected in consumer buying and consumption behavior. Lifestyle approved a multi-faceted perspective to the consumers and to portray the nature and activities of their social class or personality. (Plummer, 2010).

Lifestyle was raised for the first time by Max Weber. In 1963, Lasers "Values and Life Style" officially introduced to the field of marketing. This concept is based on the fact that people with certain patterns of living that may affect the incentives for the purchase of products and brands.

\section{4-6-Hypothesis}

H1: An exhibitions and household goods with different lifestyles will have significantly different overall behavior models.

H2: An exhibitions and household goods with different lifestyles will differ significantly in the influences of $\mathrm{AB}, \mathrm{SN}$, and $\mathrm{PBC}$ on behavioral intention.

H2.1: An exhibitions and household goods with different lifestyles will differ Significantly in the influence of $\mathrm{AB}$ on behavioral intention.

H 2.2: exhibitions and household goods with different lifestyles will differ Significantly in the influence of SN on behavioral intention.

H 2.3: exhibitions and household goods with different lifestyles will differ significantly in the influence of PBC on behavioral intention

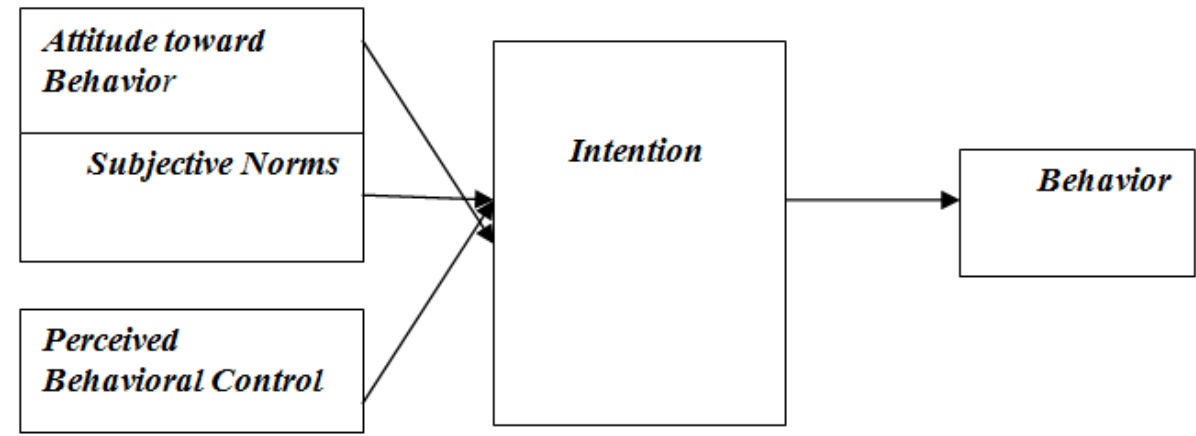

Figure 1, the relationship between the factors affecting life style, with a planned behavior ( TPB ) 
The influencing on the segmentation of consumers to use of the theory planned behavior (TPB) ..

\section{5- Sampling and Determine Sample Size}

In this study, due to lack unlikely equality for all members of the population, sampling This study possible - clustering or an area that has been chosen with Tehran divided into 4 sections (North, East, South and West), samples random or accidental available in each region were selected.

Because the next 7-point Likert scale of 1 "strongly disagree" and 7 "totally agree" on a questionnaire from a variety respectively, and is used by taking infinite population, the sample size of 384 citizens of Tehran.

\section{6- Method analysis for data's}

In this study, data for different groups of consumers using the software SPSS

(Statistical Package for the population studied) descriptive statistics based on the reliability and validity of factor analysis and cluster analysis for identification was also calculated. To the hypothesis of structural equation modeling with partial least squares approach is used. In this study we have used the software SPSS and Smart PLS.

\section{7- Model of Structural (model for analyzes the route)}

After confirming the validity and diagnostic measurement model and calculations at this stage can study to test the relationship between pay structures. In order to that got out model the software Smart PLS .

The main variables were in Table 1. The mean and standard deviation had shown index research. As you can see, mean scores of attitude toward behavior, subjective norms, perceived behavioral control and intention respectively, 86/3, 25/4, 23/4, 6/4 and 12/4. They are value scores understood, routine, family-oriented and tend to fashion respectively, 9.5, 5, 7.4 and 8.5. It is clearly that the people in the sample are demanding fashion, high value life Everyday work and family-oriented people. It is also above average scores in everyday work and family-oriented people are high.

Table 1. Index's Descriptive Measures

\begin{tabular}{|l|l|l|l|l|l|}
\hline Variable & Number of questions & Average & The standard deviation & Minimum & Maximum \\
\hline $\begin{array}{l}\text { Attitude toward behavior } \\
(X 1)\end{array}$ & 5 & $3 / 86$ & $0 / 71$ & 1 & 7 \\
\hline Subjective norm(X2) & 3 & $4 / 25$ & $1 / 02$ & 1 & 7 \\
\hline $\begin{array}{l}\text { Perceived behavioral } \\
\text { Control(X3) }\end{array}$ & 4 & $4 / 23$ & $0 / 68$ & 1 & 7 \\
\hline Intention of behavior $(Y)$ & 4 & $4 / 6$ & $0 / 8$ & 1 & 7 \\
\hline Attitude of behavior $(X)$ & 12 & $4 / 12$ & $0 / 57$ & 1 & 7 \\
\hline life quality valued $(T 1)$ & 6 & $5 / 9$ & $1 / 3$ & 1 & 7 \\
\hline routine work(T2) & 10 & 5 & $0 / 8$ & 1 & 7 \\
\hline family centered(T3) & 3 & $4 / 7$ & $0 / 69$ & 1 & 7 \\
\hline fashion inclination(T4) & 2 & $5 / 8$ & $0 / 5$ & 7 & 7 \\
\hline
\end{tabular}

In this study, using the average respondents have class, namely using the questionnaire with the quality of life, daily work, family oriented and tend to be clustered fashion people in the study have taken place.

Table 2. Results of clustering lifestyle

\begin{tabular}{|c|c|c|c|c|c|c|}
\hline \multirow{2}{*}{ Variables } & \multicolumn{2}{|c|}{ Cluster } & \multicolumn{2}{|c|}{ F } & \multirow{2}{*}{ Level of Significance } \\
\cline { 2 - 6 } & $\begin{array}{c}\text { Square of } \\
\text { mean }\end{array}$ & $\begin{array}{c}\text { Degrees of } \\
\text { freedom }\end{array}$ & $\begin{array}{c}\text { Square } \\
\text { of mean }\end{array}$ & $\begin{array}{c}\text { Degrees of } \\
\text { freedom }\end{array}$ & & \\
\hline life quality Value & $17 / 6$ & 1 & $0 / 188$ & 390 & $93 / 99$ & $0 / 00$ \\
\hline Routine work & $0 / 001$ & 1 & $0 / 211$ & 390 & $686 / 48$ & $0 / 00$ \\
\hline Family centered & $58 / 75$ & 1 & $1 / 33$ & 390 & $43 / 97$ & $0 / 00$ \\
\hline Fashion inclination & $296 / 06$ & 1 & $1 / 23$ & 390 & $239 / 4$ & $0 / 00$ \\
\hline
\end{tabular}

Table 3. Frequency of Euclidean distance between the centers of each cluster and the cluster shows the distance between the centers is higher, indicating that the dissimilarity between them is higher, and vice versa, are less indicative of similarity centers are clustered together.

According to results table below; the distance between clusters 1 and 2 is equal to 667/3.

Table 3. Intervals cluster \& frequency each cluster

\begin{tabular}{|l|l|l|l|l|l|}
\hline The cumulative percentage & \multirow{2}{*}{ Percent } & \multirow{2}{*}{ Number } & \multirow{2}{*}{ Cluster } & \multicolumn{2}{|l|}{ Distance from the cluster center } \\
\cline { 6 - 7 } & $52 / 8$ & $52 / 8$ & 207 & Cluster1 & Cluster 2 \\
\hline 100 & $47 / 2$ & 185 & Cluster 1 & & $3 / 667$ \\
\hline & 100 & 392 & Total & $3 / 66$ & \\
\hline
\end{tabular}


The influencing on the segmentation of consumers to use of the theory planned behavior (TPB) ..

Before the test, solidarity should determine the distribution variables. For this test, we use reliable and scientific ks. In this test the null hypothesis of normal distribution of data we suppose is the non-normal distribution of data Table 4: the level of significance of the test for each 4 attitude toward the behavior, subjective norms, perceived behavioral control calculated were less than 05/0,Kolmogorov's test had shown to the null hypothesis on the distribution of data is rejected and before it is confirmed.

Table 4-Data normality test results

\begin{tabular}{|c|c|c|}
\hline Variables & $\begin{array}{c}\text { statistics of } \\
\text { Kolmogorov-Smirnov }\end{array}$ & Level of Significance \\
\hline Attitude toward behavior & $0 / 144$ & $0 / 00$ \\
\hline Subjective norm & $0 / 163$ & $0 / 00$ \\
\hline Perceived behavioral control & $0 / 165$ & $0 / 00$ \\
\hline Intention of behavior & $0 / 124$ & $0 / 00$ \\
\hline
\end{tabular}

Correlation test results in Table 5:

The separated clusters and for all the people in the study is given.

The results show that 95 percent between intention and attitude toward behavior, subjective norms, perceived behavioral control and there is a significant positive correlation.

Table 5: The result Test of Spearman correlation coefficient

\begin{tabular}{|c|c|c|c|c|}
\hline & Variables & Subjective norm & Perceived behavioral control & Intention of behavior \\
\hline \multirow{4}{*}{ Cluster1 } & Attitude toward behavior & $0 / 35$ & $0 / 229$ & $0 / 346$ \\
& & $0 / 619$ & $0 / 00$ & $00 / 0$ \\
\cline { 2 - 5 } & Subjective norm & & $0 / 236$ & $0 / 363$ \\
& & $0 / 00$ & $0 / 00$ \\
\cline { 2 - 5 } & Perceived behavioral control & & & $0 / 373$ \\
& & & $0 / 00$ \\
\hline \multirow{6}{*}{ Cluster2 } & Attitude toward behavior & $0 / 123$ & $0 / 332$ & $0 / 403$ \\
& & $0 / 094$ & $0 / 00$ & $0 / 00$ \\
\cline { 2 - 5 } & Subjective norm & & $0 / 262$ & $0 / 377$ \\
& & & $0 / 00$ & $0 / 00$ \\
\cline { 2 - 5 } & Perceived behavioral control & & & $0 / 509$ \\
& & & $0 / 00$ \\
\hline \multirow{3}{*}{ Tttitude toward behavior } & $0 / 075$ & $0 / 277$ & $0 / 374$ \\
& & $0 / 135$ & $0 / 00$ & $0 / 00$ \\
\cline { 2 - 5 } & Subjective norm & & $0 / 253$ & $0 / 439$ \\
& & & $0 / 00$ & $0 / 439$ \\
\cline { 2 - 5 } & Perceived behavioral control & & & $0 / 00$ \\
\hline
\end{tabular}

In Table 6 : A measurement model is related to on the part of the general model that includes a variable with questions related to that variable.

Fitted three criteria for measuring which are used to the reliability, validity, convergent and divergent validity. Their reliability is done coefficients of three factor loadings. Cranach's alpha coefficients, the composite reliability

Table 6: operating loads and the coefficient t of with all the questions

\begin{tabular}{|c|c|c|c|c|c|c|c|}
\hline Coefficients t & $\begin{array}{l}\text { Load } \\
\text { factor }\end{array}$ & questions & variables & Coefficients $\mathrm{t}$ & $\begin{array}{l}\text { Load } \\
\text { factor }\end{array}$ & questions & variables \\
\hline $21 / 63$ & $0 / 835$ & 9 & \multirow{4}{*}{ 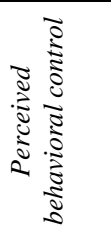 } & $9 / 581$ & $0 / 786$ & 1 & \multirow{5}{*}{ 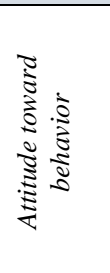 } \\
\hline $25 / 63$ & $0 / 889$ & 10 & & $25 / 375$ & $0 / 902$ & 2 & \\
\hline $32 / 09$ & $0 / 874$ & 11 & & $21 / 482$ & $0 / 879$ & 3 & \\
\hline $16 / 8$ & $0 / 83$ & 12 & & $8 / 173$ & $0 / 743$ & 4 & \\
\hline $13 / 656$ & $0 / 756$ & 13 & \multirow{4}{*}{ 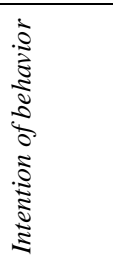 } & $26 / 381$ & $0 / 88$ & 5 & \\
\hline $20 / 997$ & $0 / 829$ & 14 & & $14 / 08$ & $0 / 82$ & 6 & \multirow{3}{*}{ 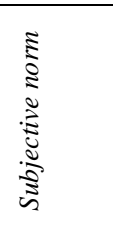 } \\
\hline $19 / 178$ & $0 / 808$ & 15 & & $15 / 78$ & $0 / 823$ & 7 & \\
\hline $24 / 36$ & $0 / 846$ & 16 & & $11 / 683$ & $0 / 802$ & 8 & \\
\hline
\end{tabular}


The influencing on the segmentation of consumers to use of the theory planned behavior (TPB) ..

In Table 7. The study shows the validity of the model. As indicated in the table is derived from the method and Larkr Fornell (1981) is the specified amount of root AVE latent variables in this study who were at home in the diagonal matrix.

The amount of correlation in the lower house and left diagonal been organized, more. Thus it can be stated that in the above model structures (latent variables) model, more interaction with their indices to other structures

In other words, the validity of divergence as a good model.

Table 7. Results divergent validity

\begin{tabular}{|c|c|c|c|c|}
\hline Structures & Attitude toward behavior & $\begin{array}{c}\text { Subjective } \\
\text { norm }\end{array}$ & $\begin{array}{c}\text { Perceived behavioral } \\
\text { control }\end{array}$ & \\
\hline Attitude toward behavior & $0 / 84$ & & & \\
\hline Subjective norm & $0 / 1$ & $0 / 814$ & & \\
\hline Perceived behavioral control & $0 / 376$ & $0 / 3$ & $0 / 857$ & \\
\hline & $0 / 38$ & $0 / 44$ & $0 / 576$ & $0 / 809$ \\
\hline
\end{tabular}
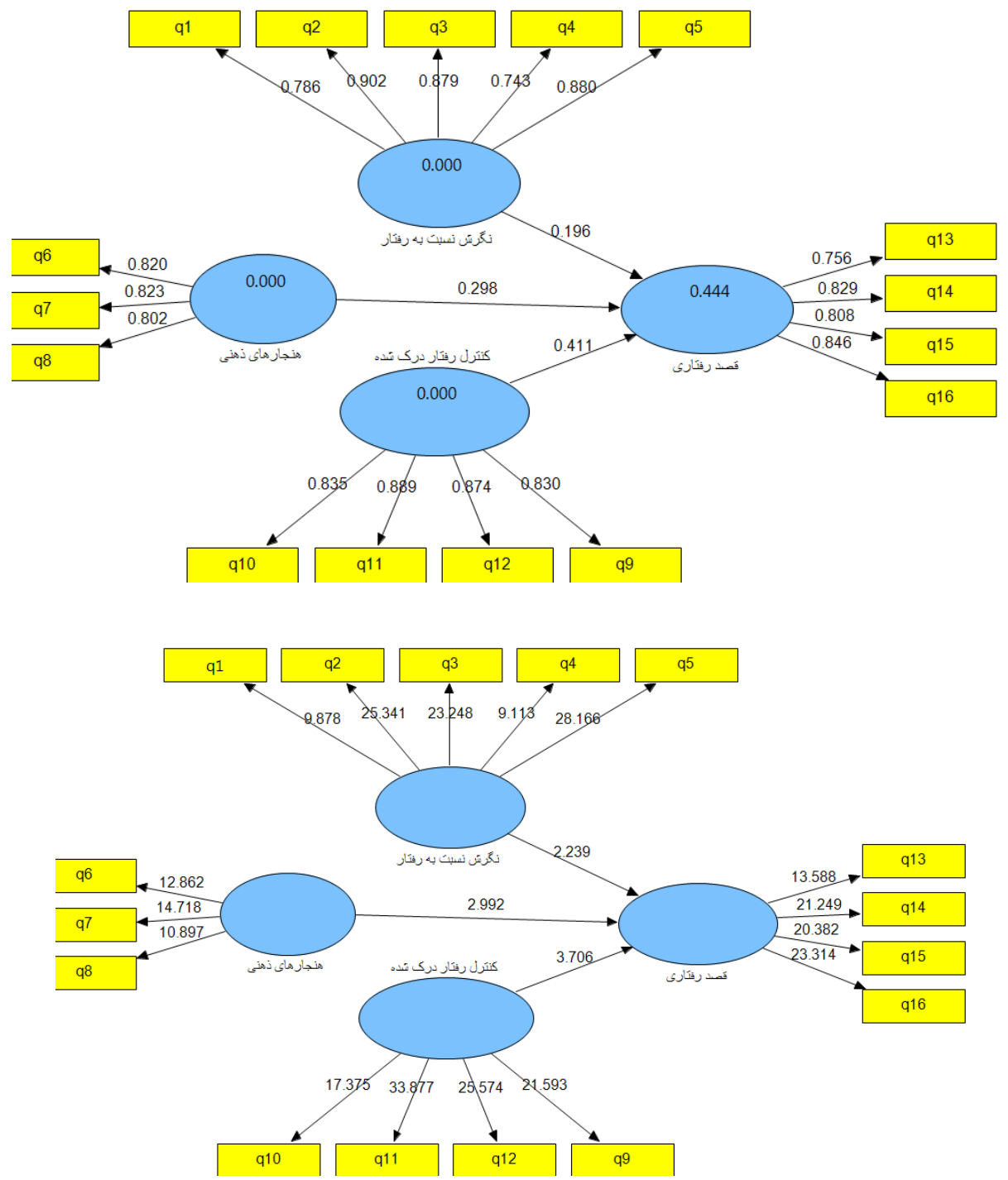

Figure 1. Standardized coefficients t-Values load factor and factor structure of the research model

\section{Conclusion}

H1: models of behavior is significant difference among people with different life styles, a significant difference. for this hypothesis was used to test Whitney

The results show that the level of 5 percent, attitudes toward the behavior, perceived behavioral control and 
intention among people with different lifestyles, these is not a significant difference.

Subjective norms of people have significant differences, with different lifestyles

$\mathrm{H} 2$ : Visitors to the exhibition of home appliances will differ in terms of lifestyles and attitudes toward behavior and subjective norms, and perceived behavioral control have significant effect on behavioral intention.

The results showed that, regardless of the type of lifestyle when we are all subjects of the study looked at the effect of the second order structures (including attitudes toward behavior and subjective norms, and perceived behavioral control) are going to be meaningful behavior. This means that people believe these variables affect the intended behavior When people with different life styles to consider, The results showed that people who have different lifestyles believe that this impact is significant. And the difference between the impact of cluster A and cluster two people in there The results showed that, when we study regardless of the type of people consider lifestyle; attitude toward behavior has a significant impact on intention to treat.

That total people believe the attitude toward the behavior intended to influence the behavior of individuals. When people to consider with different life styles, the results showed that people who have different lifestyles believe that this impact is significant. And they had impact to difference between the impact of cluster A and cluster two people in there.

H1.2: Household appliances exhibition visitors will differ in terms of lifestyle and attitude towards the behavior have effect significant on behavior intention.

The results showed, When we study regardless of the type of people consider lifestyle, attitude toward behavior intention. This is meaning significant impact on the behavior of people believe that the attitude toward the behavior intended to influence the behavior of individuals.

When people to consider with different lifestyles in mind and we went to the front group analysis, Showed that lifestyle intervention affect individuals' different attitudes toward behavior intention, and in both there is a significant impact of lifestyle.

H2.2: Household appliances exhibition visitors will differ in terms of lifestyle and behavioral intention are subjective norms significantly.

The results showed that, when we study all subjects regardless of the type of lifestyle we considered subjective norms significant impact on behavioral intention. This means that people believe in the influence of subjective norms on behavioral intention.

When people to consider with different lifestyles in mind and we went to the front group analysis, they showed that lifestyle intervention on the impact of subjective norms on behavioral intention is different and significant impact on both lifestyle.

$\mathrm{H}$ 3.3: Household appliances exhibition visitors will differ in terms of lifestyles and perceived behavioral control have a significant effect on behavioral intention.

The results showed that, when we study all subjects regardless of the type of lifestyle we considered, perceived behavioral control has a significant impact on behavioral intention.

In general, people believe that perceived behavioral control on trying to influence people's behavior.

When people to consider with different lifestyles in mind and we went to the front group analysis, the results showed that lifestyle intervention affect different people perceived behavioral control and intention not conduct significant impact on both lifestyle.

\section{Recommendations for Future Research}

a) Research on the factors influencing behavioral models based on the theory of planned behavior and lifestyle.

b) Conduct research to determine the market segmentation theory planning behavior in order to influence behavioral models.

c) Qualitative and quantitative research purposes in relation to behavior and lifestyle models in home appliances exhibition.

d) The effect of variables s theory of planned behavior on any exhibition or festival by lifestyle

e) Identify factors affecting planning marketing strategies based on lifestyle using the theory of planned behavior

[1]. Ajzen, I. and M. Fishbein (1972). Attitudes and normative beliefs as factors influencing behavioral intention. Journal of Personality and Social Psychology 21: 1-9.

[2]. Ajzen, I. (1987). Attitudes, traits, and actions: Dispositional prediction of behavior in personality and social psychology. In L. Berkowitz (Ed.), Advances in experimental social psychology (Vol. 20, pp. 1-63). New York: Academic Press

[3]. Ajzen, I. (1991). The theory of planned behavior. Organizational Behavior andHuman Decision Processes, 50, 179-211.

[4]. Ajzen, I., \& Driver, B. L. (1992). Application of the theory of planned behavior to leisure choice. Journal of Leisure Research, 24(3), 207-224.

[5]. Bessiere, J. (2010). Local development and heritage: Traditional food and cuisine as tourist attractions in rural areas. Sociologia Ruralis, 38(1), 21-34. 
[6]. Ignatov, E., \& Smith, S. (2006). Segmenting Canadian culinary tourists. Current Issues in Tourism, 9(3), 235-255.

[7]. Plummer, J. T. (2010). The concept and application of life style segmentation. Journal of Marketing, 38(1), 33-37.

[8]. Khaki, Gh. (1388). research method in management. Tehran: reflections

[9]. Lazer.(2010). Lifestyle Concepts and Marketing. Toward Scientific Marketing, American Marketing Association. 1963: 64-105.

[10]. - Smith, S. L. J., \& Xiao, H. (2008). Culinary tourism supply chains: A preliminary examination. Journal of Travel Research, 46, 289-299.

[11]. Teo, P., \& Chang, T. C. (2012). Singapore: Tourism development in a planned context. In C. M. Hall \& S. J. Page (Eds.), Tourism in south and southeast Asia, 117-128). London, UK: Routledge. 